\title{
Estabilidade oxidativa e microbiológica em carne de galinha mecanicamente separada e adicionada de antioxidantes durante período de armazenamento a $-18{ }^{\circ} \mathrm{C}$
}

\author{
Oxidative and microbiological stability of mechanically separated \\ hen meat pre blended with antioxidants during frozen storage
}

\author{
Marco Antonio TRINDADE ${ }^{1 *}$, Tatiana Pacheco NUNES ${ }^{2}$, \\ Carmen Josefina CONTRERAS-CASTILLO ${ }^{3}$, Pedro Eduardo de FELÍCIO ${ }^{4}$
}

\begin{abstract}
Resumo
Com o objetivo de acompanhar a estabilidade físico-química e microbiológica da carne mecanicamente separada (CMS) de diferentes origens e estocada durante 99 dias a $-18^{\circ} \mathrm{C}$, foi realizada prévia mistura de conservante (nitrito de sódio) e antioxidante (eritorbato de sódio) em CMS obtida de duas linhagens de aves: galinhas matrizes de corte e galinhas poedeiras comerciais brancas. Na CMS de cada linhagem foram realizados três diferentes tratamentos: 1) controle (sem aditivos); 2) adição de 150 ppm de nitrito; e 3 ) adição de 150 ppm de nitrito e 500 ppm de eritorbato. Os resultados encontrados demonstraram que a adição de nitrito isoladamente não impediu a oxidação lipídica, avaliada através do índice de TBARS, nem a alteração na cor, avaliada em colorímetro. Por outro lado, a adição de nitrito juntamente com eritorbato foi efetiva na redução dos problemas de oxidação lipídica na CMS de galinhas matrizes, e em menor grau, na CMS de poedeiras. A adição de nitrito e eritorbato na CMS também melhorou a preservação da cor vermelha desejável ( $\mathrm{a}^{*}$ ) ao longo do tempo. A avaliação da estabilidade microbiológica da CMS, realizada no primeiro e último dia de estocagem congelada, para microrganismos mesófilos, Escherichia coli, Staphylococcus aureus, Clostridium perfringens e Pseudomonas spp., e quinzenalmente para microrganismos psicrotróficos, indicou que não houve uma variação significativa nas contagens em função do tratamento utilizado (diferentes aditivos adicionados). Não foi detectada Salmonella spp. em nenhuma das amostras analisadas. Em função da melhoria da estabilidade oxidativa, recomenda-se a adição de nitrito (150 ppm) e eritorbato (500 ppm) em CMS de galinhas matrizes a ser estocada congelada por um período prolongado.
\end{abstract}

Palavras-chave: galinhas de descarte; CMS; conservação; nitrito de sódio; eritorbato de sódio.

\section{Abstract}

With the objective of following the microbiological e physical-chemical stability of mechanically separated meat (MSM) of different origins and stored during 99 days at $-18{ }^{\circ} \mathrm{C}$, a previous mixture of preservative (sodium nitrite) and antioxidant (sodium erythorbate) in MSM obtained from two poultry breeds: broiler breeders and white layers, was made. In the MSM of each breed, three different treatments were carried out: 1) control (without additives), 2) addition of $150 \mathrm{ppm}$ nitrite and 3) addition of $150 \mathrm{ppm}$ nitrite and 500 ppm erythorbate. The results obtained demonstrated that nitrite added separately did not hinder lipid oxidation, evaluated through the TBARS index, or the color changes, evaluated with a colorimeter. On the other hand, the addition of nitrite together with erythorbate was effective in reducing the problems of lipid oxidation during prolonged frozen storage. The evaluation of the microbiological stability of the MSM, carried out in the first and last day for mesophilic microorganisms, Escherichia coli, Staphylococcus aureus, Clostridium perfringens and Pseudomonas spp., and every 15 days for psycrotrophic microorganisms, did not indicate a significant variation in the counts, as a function of the treatment applied. Salmonella spp. was not detected in the samples analyzed. Considering the improvement in the oxidative stability, the addition of nitrite (150 ppm) and erythorbate (500 ppm) in MSM broiler breeders to be frozen stored for a long time can be recommended.

Keywords: spent hens; MSM; conservation; sodium nitrite; sodium erythorbate.

\section{Introdução}

No ano de 2005 foram produzidos no Brasil 9,3 milhões de toneladas de carne de frango (AVISITE, 2006). A preferência dos consumidores por cortes de frango ao invés de frangos inteiros, e posteriormente a demanda por filés e produtos de conveniência, trouxe a necessidade de se encontrar meios para aproveitar as enormes quantidades de dorsos, pescoços e ossos, resultantes dos processos de desossa. Estas partes representam cerca de $24 \%$ da porção comestível. Com isso, as carnes mecanicamente separadas (CMS) de aves estão cada vez mais disponíveis e, conseqüentemente, são mais utilizadas na fabricação de produtos processados, como salsichas e mortadelas. A CMS se caracteriza por ser muito susceptível à perda de qualidade, principalmente se não for manuseada e estocada corretamente antes de sua utilização na fabricação de embutidos.

\section{Recebido para publicação em 13/12/2006}

Aceito para publicação em 19/10/2007 (002025)

${ }^{1}$ Departamento de Engenharia de Alimentos, Faculdade de Zootecnia e Engenharia de Alimentos, Universidade de São Paulo - USP, Av. Duque de Caxias Norte, 225,

Jardim Elite, CEP 13635-900, Pirassununga-SP, Brasil, E-mail: trindadema@usp.br

2 Departamento de Alimentos e Nutrição Experimental, Faculdade de Ciências Farmacêuticas, Universidade de São Paulo - USP

${ }^{3}$ Departamento de Agroindústria, Alimentos e Nutrição da Escola Superior de Agricultura "Luiz de Queiroz", Universidade de São Paulo - USP

${ }^{4}$ Departamento de Tecnologia de Alimentos, Faculdade de Engenharia de Alimentos, Universidade Estadual de Campinas - Unicamp

${ }^{*}$ A quem a correspondência deve ser enviada 
A ruptura das membranas celulares causadas no processo de moagem ou pela separação mecânica facilita a interação dos prooxidantes com os ácidos graxos insaturados presentes na própria carne, resultando na geração de radicais livres e na propagação das reações oxidativas (GRAY; GOMAA; BUCLKEY, 1996). A separação mecânica libera grandes quantidades de lipídeos e hemoglobina da medula óssea, e a estrutura fibrosa da carne é quebrada em pequenas partículas (McMINDES; SIEDLER, 1988). Lipídeos insaturados da medula óssea, fina moagem, incorporação de ar, pigmentos heme, contato com os metais e a elevação da temperatura durante a separação mecânica contribuem para a oxidação lipídica e dos pigmentos (FIELD, 1988), o que pode levar ao aparecimento de odor de ranço e alteração na cor em CMS. A oxidação lipídica com formação de odores indesejáveis (rancidez) tem sido considerada uma das principais causas de perda de qualidade em carnes mecanicamente separadas (JANTAWAT; DAWSON, 1980; MOERCK; BALL JR, 1974), assim como em carnes e produtos cárneos em geral (GRAY; GOMAA; BUCLKEY, 1996; MORRISEY et al., 1998).

O processo de extração da CMS também propicia a formação de uma matéria-prima com elevada carga microbiana, como conseqüência da contaminação introduzida durante o processo. As pequenas partículas e a grande área de superfície, e a liberação de fluídos celulares ricos em nutrientes devido à maceração do tecido e ao calor gerado durante o processo de desossa mecânica propiciam o desenvolvimento bacteriológico (KUMAR; PEDERSEN-WISMER; CASPERSEN, 1986).

O nitrito $\left(\mathrm{NO}_{2}\right)$ é um ingrediente essencial em carnes curadas e após ser reduzido para óxido nítrico (NO) combina com a mioglobina para produzir a cor vermelha característica de produto curado cru, chamado de pigmento nitrosomioglobina (NOMb). Quando aquecido, o pigmento $\mathrm{NOMb}$ é convertido a nitroso-hemocromo, que possui a cor rósea característica de produtos curados e cozidos. Os pigmentos nitrosomioglobina (vermelho) e nitroso-hemocromo (rosado) são sensíveis à luz e à oxidação. A adição de um agente redutor favorece o desenvolvimento da coloração desejada (PRICE; SCHWEIGERT, 1971). O nitrito também age como antioxidante (POLLONIO, 1994), reduzindo a oxidação quando adicionado em doses iguais ou superiores a $50 \mathrm{ppm}$ (GRAY; PEARSON, 1987). Segundo Hasiak et al. (1984), a presença de nitrito de sódio acima de $52 \mathrm{ppm}$, em presunto de peru estocado durante 11 semanas a $2{ }^{\circ} \mathrm{C}$, reduziu significativamente $\mathrm{o}$ valor de TBA em relação ao produto sem nitrito.

Outro importante efeito atribuído ao nitrito é prevenir a produção da toxina pelo Clostridium botulinum (HASIAK et al., 1984; KOLODZIEJSKA; SKONIECSNY; RUBIN, 1990). No entanto, o teor a ser adicionado para se atingir este efeito, que varia entre 50 a $150 \mathrm{ppm}$, é dependente de inúmeros fatores, tais como: $\mathrm{pH}$ do produto, teor de nitrito residual, abuso de temperatura, teor de eritorbato ou ascorbato, teores de ferro disponíveis no produto, tipo de carne e outros ingredientes adicionados, dentre outros (TOMPKIN, 1986).

O eritorbato de sódio é o sal sódico do ácido eritórbico ou ácido isoascórbico, que é um isômero do ácido ascórbico. O eritorbato e o ascorbato de sódio são utilizados em produtos cárneos com as funções principais de acelerar a formação da cor e estabilizar a cor característica de carnes curadas com nitrito em função de seu alto poder redutor (COUNSELL; HORNIG, 1981). Além da reação com o nitrito, o eritorbato por si só apresenta um forte efeito antioxidante, prevenindo o desenvolvimento de rancidez oxidativa, quando aplicado em concentrações acima de 100 ppm, sendo que em concentrações mais baixas pode acelerar o desenvolvimento da rancidez oxidativa (GRAY; PEARSON, 1987). Saleh e Watts, apud Gray e Pearson (1987) demonstraram que a atividade redutora em carnes cruas tem uma função importante na prevenção da oxidação, sendo que a adição de substâncias que proviam elétrons para a metamioglobina mantinham a carne no estado reduzido, efetivamente retardando a oxidação. Segundo estes autores, em níveis elevados, os ascorbatos funcionariam criando condições redutoras, enquanto que em baixos níveis eles seriam rapidamente exauridos, não conseguindo manter as condições redutoras e acelerando a oxidação.

O objetivo deste trabalho foi acompanhar a estabilidade físico-química (através do índice de TBARS e da cor objetiva) e microbiológica (através da contagem de microrganismos psicrotróficos e mesófilos aeróbios, Staphylococccus aureus, Clostridium perfringens, Salmonella spp., Pseudomonas spp. e E. coli) de carnes mecanicamente separadas (CMS) obtidas de duas diferentes linhagens de aves (galinhas matrizes de corte e galinhas poedeiras comerciais brancas) e estocadas durante 99 dias a $-18{ }^{\circ} \mathrm{C}$, com a prévia mistura de conservante (nitrito de sódio) e antioxidante (eritorbato de sódio).

\section{Material e métodos}

\subsection{Matérias-primas}

O presente trabalho foi realizado utilizando-se duas diferentes linhagens de galinhas de descarte: matrizes pesadas de corte (Cobb 500, com aproximadamente 15 meses de idade) e poedeiras comerciais brancas (Leghorn, com aproximadamente 18 meses de idade). Todo o experimento foi realizado em três repetições. Em cada repetição, foram mecanicamente desossados em torno de $150 \mathrm{Kg}$ de matrizes de corte (equivalentes a aproximadamente 45 carcaças, pesando entre 3,0 e 3,5 Kg cada) e $150 \mathrm{Kg}$ de poedeiras comerciais (equivalentes a aproximadamente 110 carcaças, pesando entre 1,0 e 1,5 Kg cada).

\subsection{Obtenção das carnes mecanicamente separadas}

As galinhas utilizadas foram cedidas por um abatedouro do interior do Estado de São Paulo, no qual foram abatidas, embaladas e resfriadas. As carcaças recebidas foram desembaladas, retirando-se em seguida os filés de peito (que foram utilizados em um estudo paralelo com relação ao seu potencial para a elaboração de nuggets). Os miúdos que acompanhavam as carcaças foram descartados. Após a retirada dos filés de peito, as carcaças foram separadas em cortes (asas, pernas, dorso e quilha do peito), para facilitar a desossa mecânica. Com exceção do peito, nenhum corte foi desossado manualmente antes da separação mecânica. 
A extração mecânica foi realizada em extratora POSS, modelo PDE 1000 (Poss Limited, Hamilton, Ontário, Canadá), com rendimentos de CMS próximos a 70\%.

\subsection{Adição de nitrito e eritorbato nas carnes mecanicamente separadas}

Após a obtenção dos dois diferentes tipos de CMS (CMS de matrizes de corte: CMSMC e CMS de poedeiras comerciais: CMSPC), separou-se cada tipo em três partes, em que o peso de cada uma foi de 9,5 Kg. Os aditivos utilizados foram previamente dissolvidos em $0,5 \mathrm{Kg}$ de água destilada para garantir melhor distribuição destes na CMS. A homogeneização da solução de aditivos e a CMS foi realizada em misturador (CAF, modelo M-60, Rio Claro - SP, Brasil), durante 3 minutos, perfazendo $10 \mathrm{Kg}$ de mistura (9,5 $\mathrm{Kg}$ de CMS mais $0,5 \mathrm{Kg}$ de água) para cada tratamento. Após a homogeneização cada tratamento foi dividido em porções de aproximadamente $400 \mathrm{~g}$, que foram embaladas em sacos de polietileno e posteriormente congeladas e estocadas a $-18^{\circ} \mathrm{C}\left( \pm 1{ }^{\circ} \mathrm{C}\right)$ durante 99 dias, com exceção daquelas amostras que seriam analisadas no dia seguinte ao processamento ( $1^{\circ}$ dia de análise), que foram armazenadas refrigeradas (entre 0 e $2{ }^{\circ} \mathrm{C}$ ) até o momento das análises.

Para cada tipo de CMS, foram realizados três tratamentos divididos da seguinte maneira: Tratamento 1 (Controle, apenas com água destilada); Tratamento 2 (150 ppm de nitrito, ou seja, $1,5 \mathrm{~g}$ de nitrito dissolvido na água destilada) e Tratamento 3 (150 ppm de nitrito e $500 \mathrm{ppm}$ de eritorbato, ou seja, $1,5 \mathrm{~g}$ de nitrito de sódio-Merck e 5,0 g de eritorbato de sódio-DiCarne).

Os seis tratamentos avaliados e suas respectivas abreviações estão detalhados abaixo:

- MC: CMS de matriz pesada de corte (CMSMP) onde não foi adicionado aditivo;

- MN: CMSMP pré-curada com nitrito de sódio;

- MNE: CMSMP pré-curada com nitrito de sódio e eritorbato de sódio;

- PC: CMS de poedeira comercial branca (CMSPC) onde não foi adicionado aditivo;

- PN: CMSPC pré-curada com nitrito de sódio; e

- PNE: CMSPC pré-curada com nitrito de sódio e eritorbato de sódio.

\subsection{Avaliação da estabilidade oxidativa}

As análises foram realizadas nos seguintes intervalos de tempo: 1, 15, 29, 43, 57, 71, 85 e $99^{\circ}$ dia após a extração da CMS. Antes de cada dia de análise as amostras foram colocadas para descongelamento em câmara fria entre 0 e $2{ }^{\circ} \mathrm{C}$ durante cerca de 12 horas, com exceção das amostras analisadas no $1^{\circ}$ dia, que não foram congeladas. No momento das análises as amostras apresentavam temperaturas próximas a $0^{\circ} \mathrm{C}$.

A cor objetiva foi determinada através de colorímetro portátil (Minolta, modelo CM508d, Ramsey, New Jersey, U.S.A.), utilizando iluminante $\mathrm{C}$ com ângulo de abertura de $2^{\circ}$, no sistema CIE $L^{\star} a^{\star} b^{\star}$. Foram tomadas 6 medidas para cada amostra.
Após a tomada das medidas de cor objetiva, as amostras foram homogeneizadas em processador de alimentos WALITA MASTER durante 40 segundos, na velocidade máxima, antes da realização das análises de TBARS, nitrito e pH.

O método de extração direta (VINCKE, 1975) foi utilizado para medir o desenvolvimento de substâncias reativas ao ácido tiobarbitúrico (TBARS). Os resultados foram expressos em mg malonaldeído/Kg amostra.

Os teores de nitrito foram determinados utilizando metodologia oficial do Ministério da Agricultura e Abastecimento (BIJKER; LOGTESTIJN; MOSSEL, 1987).

$\mathrm{O} \mathrm{pH}$ foi medido em pHmetro (Digimed, modelo DM-20, Santo Amaro, São Paulo, Brazil) com eletrodo de punção (Digimed, modelo DME-CF1) diretamente na amostra.

\subsection{Avaliação da estabilidade microbiológica}

As análises microbiológicas para os microrganismos psicrotróficos aeróbios foram realizadas no 1, 15, 29, 43, 57, 71, 85 e $99^{\circ}$ dia de armazenamento. Enquanto que para os microrganismos mesófilos aeróbios, Staphylococcus aureus, Clostridium perfringes, Salmonella spp., Pseudomonas spp. e E. coli somente no $1^{\circ}$ dia (dia seguinte à extração) e no $99^{\circ}$ dia de armazenamento a $-18^{\circ} \mathrm{C}$ (Tabela 1$)$.

Exceto para as análises de Pseudomonas spp. e Staphylococcus aureus, que seguiram metodologia segundo Mead e Adams (1977) e Silva (1994), respectivamente, todas as demais análises foram realizadas de acordo com a metodologia descrita por Vanderzant e Splittstoesser (1992).

\subsection{Análises estatísticas}

Foi aplicado um delineamento completamente casualizado com 3 repetições e 3 tratamentos para cada um dos 2 tipos de aves, com medidas realizadas em 7 intervalos de tempo. Os dados foram analisados por ANOVA para comparar os resultados entre os tratamentos de cada ave e regressão para estudar as tendências durante o período avaliado. As médias foram comparadas pelo teste de Tukey. Em todas as análises o nível de significância $\mathrm{p}<0,05$ foi adotado.

\section{Resultados e discussão}

\subsection{Teores de nitrito residual}

Os teores de nitrito residual dos tratamentos MN e MNE não diferiram $(\mathrm{p}>0,05)$ e apresentaram um comportamento semelhante $(\mathrm{p}>0,05)$ de queda ao longo do tempo $(\mathrm{p}<0,05)$, variando de 145 e 139 ppm no primeiro dia para 109 e $102 \mathrm{ppm}$ após 99 dias de estocagem, respectivamente. Os teores de nitrito residual dos tratamentos PN e PNE variaram, respectivamente, de 130 e $121 \mathrm{ppm}$ no primeiro dia até 95 e $81 \mathrm{ppm}$ no $99^{\circ}$ dia da estocagem congelada. $\mathrm{O}$ modelo de regressão apresentou um efeito linear $(\mathrm{p}<0,05)$ de queda do teor de nitrito residual, para ambos os tratamentos (PN e PNE). Hasiak et al. (1984) também verificaram um declínio linear do nitrito residual em presunto cozido de peru, fatiado e embalado a vácuo e estocado 
Tabela 1. Dias da realização das análises microbiológicas e microrganismos avaliados nas carnes CMS durante período de armazenamento.

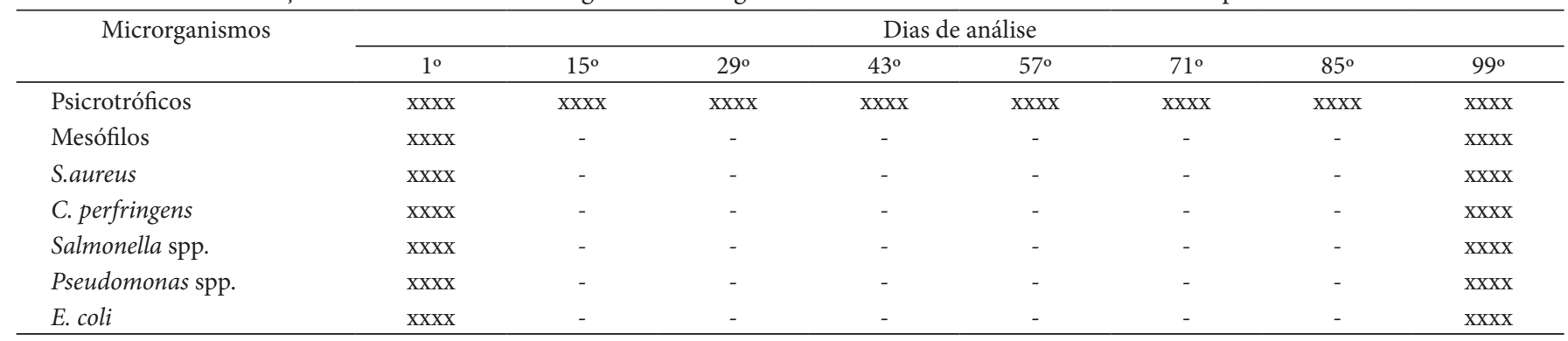

sob refrigeração a $2{ }^{\circ} \mathrm{C}$ por 11 semanas. Este comportamento de queda do teor de nitrito residual ao longo da estocagem de produtos cárneos curados se deve à reatividade do nitrito com proteínas heme e não-heme, peptídeos, aminoácidos e metais (MAC DONALD; GRAY; GIBBINS, 1980).

Apesar das médias dos tratamentos PN e PNE não serem consideradas diferentes $(p>0,05)$ nos intervalos de tempo avaliados, a média geral (incluindo todos os intervalos) diferiu $(\mathrm{p}<0,05)$, sendo o teor de nitrito de PN superior ao de PNE. É interessante notar que os tratamentos com nitrito e eritorbato (MNE e PNE), que apresentaram menores valores de nitrito residual ao final do período de estocagem, apresentaram valores de $\mathrm{a}^{*}$ superiores $(\mathrm{p}<0,05)$ aos tratamentos com apenas nitrito (MN e PN) após 99 dias. Isto ocorreu porque o eritorbato catalisou a reação de redução do nitrito a óxido nítrico, favorecendo assim a formação do pigmento nitrosomioglobina (de cor vermelha). Wesley, Marion e Sebranek (1982) também observaram este efeito em salsichas elaboradas com CMS de peru, contendo diferentes concentrações de nitrito e 550 ppm de eritorbato.

\subsection{Valores de $p H$}

Os valores de $\mathrm{pH}$ obtidos ficaram próximos de 6,4 e 6,6 nos diferentes tratamentos da CMSMP e CMSPC, respectivamente, não sendo observadas diferenças $(p>0,05)$ ao longo dos 99 dias de estocagem. Estes valores estão de acordo com aqueles observados por Pollonio (1994), que ficaram entre 6,20 e 6,37 nos diferentes tratamentos em CMS de frango (controle e misturada com nitrito ou ascorbato de sódio), também estocadas congeladas por 6 meses.

A reação do nitrito $\left(\mathrm{NO}_{2}\right)$ com os pigmentos da carne (mioglobina e hemoglobina) passa por uma série de transformações que são favorecidas pelo $\mathrm{pH}$ (passagem do $\mathrm{NO}_{2}$ para ácido nitroso), sendo este pH ótimo em torno de 5,7 (TERRA, 1998). Apesar de ter sido verificada uma queda linear dos teores de $\mathrm{NO}_{2}$ em todos os tratamentos, esta queda não foi muito pronunciada. Os altos valores de $\mathrm{pH}$ (acima de 6,4) apresentados pelas CMS e a baixa temperatura de estocagem empregada não favoreceram a formação do ácido nitroso com a conseqüente depleção dos teores de $\mathrm{NO}_{2}$. É importante salientar que as CMS apresentam normalmente valores de $\mathrm{pH}$ mais elevados (na faixa de 6,5-7,0) do que as carnes desossadas manualmente (nas faixas de 5,8-5,9 para carne de peito e 6,2-6,3 para coxa) (BERAQUET, 2000), principalmente devido à incorporação da medula vermelha, a qual apresenta $\mathrm{pH}$ na faixa de 6,8-7,4 (DENG et al., 1978). No entanto, apesar de também apresentarem valores elevados de $\mathrm{pH}$, os tratamentos com adição de eritorbato (MNE e PNE) apresentaram uma maior depleção dos teores de nitrito. Esta maior depleção deve ter sido causada devido ao forte poder redutor do eritorbato, uma vez que a transformação do ácido nitroso em óxido nítrico e a reação deste com o mioglobina são favorecidas por condições redutoras (TERRA, 1998).

\subsection{Oxidação lipídica}

Os valores de TBARS encontrados nos diferentes tratamentos para CMSMP e CMSPC ao longo de 99 dias de estocagem congelada são mostrados na Tabela 2. Os tratamentos $\mathrm{MC}$ e $\mathrm{MN}$ não se diferenciaram significativamente $(\mathrm{p}<0,05)$ em todos os dias analisados em relação aos valores de TBARS (Tabela 2). O tratamento MNE que não apresentou variação $(p>0,05)$ na oxidação durante o tempo de estocagem se diferenciou significativamente $(\mathrm{p}<0,05)$ dos tratamentos MC e $\mathrm{MN}$, do $29^{\circ}$ dia em diante. Portanto, a adição de nitrito sozinho (MN) não foi efetiva no controle da oxidação lipídica, sendo que este tratamento apresentou um comportamento similar ao MC. Talvez a concentração de nitrito utilizada neste trabalho (150 ppm) não tenha sido suficiente para neutralizar os vários fatores pró-oxidantes presentes nas CMS de galinhas. Estes dados estão de acordo com aqueles relatados por Wesley, Marion e Sebranek (1982), que não verificaram efeito significativo da adição de diversas concentrações (até 150 ppm) de nitrito sobre os índices de TBARS durante a estocagem de salsichas à base de CMS de perus, mas verificaram que a adição de 550 ppm de eritorbato de sódio reduziu o desenvolvimento da rancidez. No entanto, estão em desacordo com os resultados obtidos por Pollonio (1994), que observou forte poder antioxidante com a adição de nitrito isoladamente (200 ppm) sobre CMS de frango estocada congelada, e com Hasiak et al. (1984), que também relataram que a adição de apenas nitrito (52 $\mathrm{ppm}$ ) em presunto de peru já reduziu significativamente o valor de TBA em relação ao produto sem nitrito.

A adição de eritorbato de sódio juntamente com o nitrito na CMS de galinhas matrizes (tratamento MNE) inibiu quase completamente a oxidação lipídica. O tratamento MNE apresentou valores de TBARS abaixo de 1,0 (mg malonaldeído/Kg amostra) durante todo o período analisado. Odores de ranço podem ser detectados por provadores treinados e não treinados com TBARS na faixa de 0,5 - 1,0 e 0,6 - 2,0 mg malonaldeído/Kg amostra, respectivamente (COUNSELL; HORNIG, 1981). Utilizando-se desses valores, pode-se dizer que o tratamento 
Tabela 2. Valores médios das análises de TBARS (mg malonaldeído/Kg amostra) nas CMS de galinhas matrizes e poedeiras ao longo da estocagem congelada.

\begin{tabular}{|c|c|c|c|c|c|c|c|c|c|}
\hline & & \multicolumn{8}{|c|}{ Tempo (dias) } \\
\hline & & $1^{\circ}$ & $15^{\circ}$ & $29^{\circ}$ & $43^{\circ}$ & $57^{\circ}$ & $71^{\circ}$ & $85^{\circ}$ & $99^{\circ}$ \\
\hline \multirow[t]{2}{*}{$\mathrm{MC}$} & Média & $0,43^{\mathrm{a}}$ & $1,99^{\mathrm{a}}$ & $2,36^{a}$ & $3,20^{\mathrm{a}}$ & $3,84^{\mathrm{a}}$ & $4,10^{\mathrm{a}}$ & $3,59^{\mathrm{a}}$ & $3,43^{\mathrm{a}}$ \\
\hline & $\mathrm{EP}$ & 0,06 & 1,17 & 0,68 & 1,35 & 1,21 & 1,05 & 0,51 & 0,68 \\
\hline \multirow[t]{2}{*}{ MN } & Média & $0,44^{\mathrm{a}}$ & $0,91^{\mathrm{a}}$ & $1,89^{\mathrm{a}}$ & $3,25^{\mathrm{a}}$ & $3,32^{\mathrm{a}}$ & $3,66^{\mathrm{a}}$ & $3,52^{\mathrm{a}}$ & $3,84^{\mathrm{a}}$ \\
\hline & $\mathrm{EP}$ & 0,15 & 0,34 & 0,40 & 1,87 & 1,47 & 0,91 & 0,81 & 0,54 \\
\hline MNE & Média & $0,49^{\mathrm{a}}$ & $0,69^{\mathrm{a}}$ & $0,54^{\mathrm{b}}$ & $0,54^{\mathrm{b}}$ & $0,58^{\mathrm{b}}$ & $0,60^{\mathrm{b}}$ & $0,64^{\mathrm{b}}$ & $0,92^{\mathrm{b}}$ \\
\hline PC & $\mathrm{EP}$ & 0,19 & 1,07 & 1,24 & 1,76 & 1,91 & 1,17 & 0,26 & 0,35 \\
\hline \multirow[t]{2}{*}{$\mathrm{PN}$} & Média & $0,48^{\mathrm{a}}$ & $1,78^{\mathrm{a}}$ & $2,77^{\mathrm{a}}$ & $3,74^{\mathrm{a}}$ & $3,9^{\mathrm{a}}$ & $4,37^{\mathrm{a}}$ & $3,73^{\mathrm{a}}$ & $3,19^{\mathrm{a}}$ \\
\hline & $\mathrm{EP}$ & 0,44 & 0,85 & 0,61 & 1,22 & 1,11 & 1,07 & 0,67 & 0,60 \\
\hline \multirow[t]{2}{*}{ PNE } & Média & $0,27^{\mathrm{a}}$ & $0,38^{\mathrm{a}}$ & $1,04^{\mathrm{a}}$ & $1,42^{\mathrm{a}}$ & $1,91^{\mathrm{a}}$ & $2,62^{\mathrm{a}}$ & $2,29^{a}$ & $2,39^{\mathrm{a}}$ \\
\hline & $\mathrm{EP}$ & 0,18 & 0,09 & 1,06 & 0,84 & 1,35 & 1,96 & 1,43 & 0,72 \\
\hline
\end{tabular}

Médias com letras iguais na mesma coluna, para a mesma galinha, não apresentam diferenças ( $\mathrm{p}>0,05)$; MC: CMS de matriz pesada sem aditivos (controle); MN: CMS de matriz pesada pré-curada com nitrito de sódio (150 ppm); MNE: CMS de matriz pesada pré-curada com nitrito (150 ppm) e eritorbato de sódio (500 ppm); PC: CMS de poedeira comercial sem aditivos (controle); PN: CMS de poedeira comercial pré-curada com nitrito de sódio (150 ppm); PNE: CMS de poedeira comercial pré-curada com nitrito (150 ppm) e eritorbato de sódio (500 ppm); e EP: erro padrão.

MNE se manteve adequado para utilização, ou seja, não apresentou odores detectáveis de rancidez mesmo após 99 dias de estocagem.

Com relação aos tratamentos PC, PN e PNE (Tabela 2), os índices de TBARS não diferiram $(\mathrm{p}>0,05)$ em todos os intervalos de tempo avaliados, apresentando valores de TBARS acima de 2,0 aos 99 dias. Conseqüentemente os odores de ranço já seriam sensorialmente detectáveis (COUNSELL; HORNIG, 1981), impedindo (ou limitando) portanto a utilização das CMS de galinhas poedeiras nestas condições estudadas (Tabela 2). No entanto, utilizando-se análise por contrastes ortogonais (PROC MIXED do SAS) concluiu-se que as taxas de crescimento dos tratamentos PC e PN são iguais ( $p>0,05)$ e superiores $(\mathrm{p}<0,05)$ às do tratamento PNE. Ou seja, apesar de PNE apresentar um certo grau de oxidação durante o tempo avaliado (diferentemente de MNE que não sofreu oxidação), esta oxidação foi menor do que em PC e PN.

A ação do ascorbato (um isômero do eritorbato) em alimentos depende de vários fatores, como: potencial de óxido-redução do sistema, pH, atmosfera aeróbia ou anaeróbia, presença de metais e quantidade de ascorbato em relação às concentrações de agentes oxidantes (DENG, 1978). Sendo o eritorbato um isômero do ascorbato, pode-se esperar uma atuação semelhante destes produtos. Assim sendo, na concentração adicionada (500 ppm), o eritorbato pode não ter sido suficiente para contrabalançar os fatores envolvidos no processo de oxidação da CMS de galinhas poedeiras. Uma possível explicação pode ser o valor de $\mathrm{pH}$, ligeiramente mais elevado na CMS de poedeiras $(6,6)$ do que na CMS de matrizes $(6,4)$, haja vista, que quanto maior o valor do pH maior a oxidação lipídica (KUMAR; PEDERSEN-WISMER; CASPERSEN, 1986).

\subsection{Cor vermelha - valores de $a^{*}$}

O comportamento dos valores de $\mathrm{a}^{\star}$ (cor vermelha) ao longo dos 99 dias de estocagem refrigerada são apresentados na Tabela 3. Os valores de $\mathrm{a}^{\star}$ para os três diferentes tratamen- tos, tanto na CMSMP quanto na CMSPC, diferiram entre si $(\mathrm{p}<0,05)$ e variaram ao longo do tempo $(\mathrm{p}<0,05)$, mas sem apresentar o mesmo comportamento. No entanto, percebe-se que os tratamentos similares nas CMS das duas diferentes linhagens apresentaram um comportamento semelhante ao longo do tempo de estocagem. Observou-se que no primeiro dia após a extração das CMS, as amostras controle (MC e PC) apresentavam valores de $\mathrm{a}^{\star}$ significativamente mais elevados, portanto, uma coloração vermelha mais intensa em relação às amostras pré-curadas, tanto com nitrito ( $\mathrm{MN}$ e $\mathrm{PN}$ ) quanto com nitrito e eritorbato (MNE e PNE). A partir de 15 dias de estocagem praticamente não se observaram mais diferenças entre os diferentes tratamentos nas CMS provenientes dos dois tipos de matérias-primas. Sabe-se que os pigmentos heme presentes nas CMS estão inicialmente na forma oxigenada devido à incorporação de ar durante o processo de desossa mecânica. Segundo Price e Schweigert (1971), quando o nitrito é adicionado a uma carne nestas condições a primeira reação que ocorre é a oxidação dos pigmentos para metamioglobina. A metamioglobina precisa então ser reduzida e combinada com o óxido nítrico para formar o pigmento final desejado, a nitrosomioglonina. Ainda, segundo estes autores, parece haver várias alternativas nas quais a metamioglobina pode ser convertida ao pigmento curado. A metamioglobina pode combinar-se diretamente com o óxido nítrico para formar a nitrosometamioglobina, que deve então ser reduzida diretamente para formar a nitrosomioglobina. Neste sentido, parece que no primeiro dia os pigmentos das CMS précuradas com nitrito ou com nitrito e eritorbato apresentavam-se nas formas oxidadas metamioglobina e metahemoglobina, ou ainda, nitrosometamioglobina e nitrosometahemoglobina.

Nos períodos finais de análise, pôde-se observar uma tendência de aumento da intensidade da cor vermelha nas amostras MNE e PNE. De acordo com Pollonio (1994), a oxidação dos pigmentos heme constitui-se fator determinante da oxidação lipídica em CMS de frango. Na mesma pesquisa, a diminuição dos pigmentos heme esteve altamente correlacionada com a redução do valor a* (intensidade da cor vermelha). Estas informações 
Tabela 3. Médias dos valores de $\mathrm{a}^{\star}$ (cor vermelha) nas CMS de galinhas matrizes e poedeiras ao longo da estocagem congelada.

\begin{tabular}{|c|c|c|c|c|c|c|c|c|c|}
\hline & & \multicolumn{8}{|c|}{ Tempo (dias) } \\
\hline & & $1^{\circ}$ & $15^{\circ}$ & $29^{\circ}$ & $43^{\circ}$ & $57^{\circ}$ & $71^{\circ}$ & $85^{\circ}$ & $99^{\circ}$ \\
\hline \multirow[t]{2}{*}{$\mathrm{MC}$} & Média & $9,82^{\mathrm{a}}$ & $6,55^{\mathrm{a}}$ & $6,55^{\mathrm{a}}$ & $5,85^{\mathrm{a}}$ & $5,12^{\mathrm{a}}$ & $5,61^{\mathrm{a}, \mathrm{b}}$ & $5,22^{\mathrm{a}}$ & 4,64 \\
\hline & $\mathrm{EP}$ & 0,48 & 1,76 & 1,76 & 1,40 & 1,24 & 0,48 & 0,33 & 0,51 \\
\hline \multirow[t]{2}{*}{$\mathrm{MN}$} & Média & $4,68^{\mathrm{b}}$ & $5,02^{\mathrm{a}}$ & $5,00^{\mathrm{a}}$ & $4,58^{\mathrm{a}}$ & $4,87^{\mathrm{a}}$ & $4,64^{\mathrm{a}}$ & $4,41^{\mathrm{b}}$ & $4,22^{\circ}$ \\
\hline & $\mathrm{EP}$ & 0,08 & 0,33 & 0,24 & 0,62 & 0,80 & 0,35 & 0,25 & 0,50 \\
\hline \multirow[t]{2}{*}{ MNE } & Média & $4,39^{b}$ & $6,18^{\mathrm{a}}$ & $6,46^{\mathrm{a}}$ & $6,12^{\mathrm{a}}$ & $6,04^{\mathrm{a}}$ & $6,63^{b}$ & $6,17^{c}$ & $6,00^{\mathrm{l}}$ \\
\hline & EP & 0,27 & 0,73 & 0,52 & 0,65 & 0,77 & 0,48 & 0,25 & 0,42 \\
\hline \multirow[t]{2}{*}{ PC } & Média & $13,14^{\mathrm{a}}$ & $9,86^{\mathrm{a}}$ & $7,56^{\mathrm{a}}$ & $7,66^{\mathrm{a}}$ & $6,75^{\mathrm{a}}$ & $7,14^{\mathrm{a}, \mathrm{b}}$ & $7,34^{\mathrm{a}}$ & $7,36^{\circ}$ \\
\hline & EP & 0,72 & 1,71 & 0,86 & 1,43 & 0,59 & 0,85 & 0,79 & 1,28 \\
\hline \multirow[t]{2}{*}{ PN } & Média & $6,17^{\mathrm{b}}$ & $7,10^{\mathrm{a}}$ & $6,79^{a}$ & $6,47^{\mathrm{a}}$ & $5,80^{\mathrm{a}}$ & $5,94^{\mathrm{a}}$ & $5,76^{\mathrm{a}}$ & $4,85^{!}$ \\
\hline & $\mathrm{EP}$ & 0,64 & 0,78 & 0,41 & 1,14 & 0,74 & 0,31 & 0,91 & 0,78 \\
\hline \multirow[t]{2}{*}{ PNE } & Média & $6,31^{b}$ & $7,36^{\mathrm{a}}$ & $7,74^{\mathrm{a}}$ & $7,43^{\mathrm{a}}$ & $7,73^{\mathrm{a}}$ & $8,64^{\mathrm{b}}$ & $7,86^{\mathrm{a}}$ & 8,09 \\
\hline & EP & 0,55 & 0,92 & 0,67 & 0,95 & 1,12 & 1,37 & 0,91 & 0,11 \\
\hline
\end{tabular}

Médias com letras iguais na mesma coluna, para a mesma galinha, não apresentam diferenças ( $\mathrm{p}>0,05)$; MC: CMS de matriz pesada sem aditivos (controle); MN: CMS de matriz pesada pré-curada com nitrito de sódio (150 ppm); MNE: CMS de matriz pesada pré-curada com nitrito (150 ppm) e eritorbato de sódio (500 ppm); PC: CMS de poedeira comercial sem aditivos (controle); PN: CMS de poedeira comercial pré-curada com nitrito de sódio (150 ppm); PNE: CMS de poedeira comercial pré-curada com nitrito (150 ppm) e eritorbato de sódio (500 ppm); e EP: erro padrão.

estão de acordo com os dados obtidos neste trabalho para a CMSMP. O tratamento MNE apresentou valor de $\mathrm{a}^{*}$ superior $(\mathrm{p}<0,05)$ aos tratamentos $\mathrm{MC}$ e $\mathrm{MN}$ após 99 dias de estocagem, ao mesmo tempo em que apresentou índice de TBARS (Tabela 2) menor $(\mathrm{p}<0,05)$ que $\mathrm{MC}$ e MN. Comportamento similar, porém de forma menos acentuada, também pôde ser observado nos diferentes tratamentos da CMSPC.

\subsection{Estabilidade microbiológica}

As variações nas contagens médias de mesófilos aeróbios, Pseudomonas spp., E. coli e C. perfringens durante a estocagem congelada dos diferentes tratamentos das CMS de galinhas poedeiras e matrizes são apresentadas nas Figuras 1 e 2, respectivamente. Os tratamentos controle das galinhas poedeiras (PC) e das galinhas matrizes (MC) apresentaram contagens máximas para coliformes fecais de $2,2 \log _{10} \mathrm{UFC} \mathrm{g}^{-1}$ e para Clostridium perfringens de $1,2 \log _{10}$ UFC. ${ }^{-1}$ no $1^{\circ}$ dia de análise (Figura 1 e 2). Essas contagens foram inferiores às encontradas por Kumar, Pedersen-Wismer e Caspersen (1986) em CMS de galinhas, cujas contagens foram $4,3 \log _{10}$ UFC.g ${ }^{-1}$ para coliformes fecais e de $4,11 \log _{10}$ UFC.g ${ }^{-1}$ para Clostridium perfringens. A diferença encontrada entre as populações dos microrganismos analisados nos dois trabalhos pode estar relacionada com a qualidade microbiológica inicial da matéria-prima.

A resolução RDC no 12 da Agência Nacional de Vigilância Sanitária (ANVISA), de 12 de janeiro de 2001 (ANVISA, 2007), estabelece para carnes resfriadas ou congeladas in natura de aves (carcaças inteiras, fracionadas ou cortes) como único indicativo microbiológico o número de coliformes fecais, sendo este estipulado em $10^{4} \mathrm{NMP}^{-1}$. Como a média dos valores obtidos no presente trabalho ficou próxima a $10^{2} \mathrm{NMP}^{-1}$, tanto para a CMS de galinha matriz quanto de galinha poedeira, pode-se dizer que as CMS obtidas atenderam perfeitamente aos padrões microbiológicos da Legislação Brasileira.

Verificou-se que os tratamentos com nitrito e nitrito mais eritorbato não causaram uma redução significativa $(p>0,05)$ em relação aos tratamentos controle nas contagens de mesófilos aeróbios, Pseudomonas spp. e E. coli, tanto quando se comparam os dados no primeiro dia de estocagem quanto no $99^{\circ}$ dia. Por outro lado, nos tratamentos com nitrito e nitrito + eritorbato, o tempo de estocagem congelada reduziu significativamente $(\mathrm{p}<0,05)$ as cargas microbianas de Pseudomonas, mesófilos e E. coli nas CMS de galinhas poedeiras (PN e PNE), sendo esta redução significativa $(\mathrm{p}<0,05)$ somente para mesófilos nas CMS de galinhas matrizes ( $\mathrm{MN}$ e MNE). Já com relação às contagens de $C$. perfringens, observou-se que o tempo de congelamento (dias 1 e 99) reduziu significativamente $(\mathrm{p}<0,05)$ essa população também nas CMS controle (MC e PC), bem como quando se comparam estes tratamentos, no primeiro dia de estocagem, com os tratamentos nitrito ( $\mathrm{PN}$ e $\mathrm{MN}$ ) e nitrito mais eritorbato (PNE e MNE). Esses resultados estão de acordo com White e Hall (1984), os quais afirmaram que essa bactéria é altamente sensível ao congelamento, contrariando o comportamento de outras bactérias causadoras de intoxicações. Aliado a esse fator, existe o efeito inibitório do nitrito de sódio sobre as bactérias do gênero Clostridium (McNEILL; KAKUDA, 1988; CARPENTER; REDDY; CORNFORTH, 1987).

Não foi detectada a presença de Salmonella spp. e Staphylococcus aureus em nenhuma das amostras analisadas durante todo o período de estocagem congelada avaliado.

Nas Figuras 3 e 4 é possível observar o comportamento dos microrganismos psicrotróficos aeróbios, nas CMS de galinhas poedeiras e de matrizes, respectivamente, ao longo dos 99 dias de armazenamento $\mathrm{a}-18^{\circ} \mathrm{C}$. As contagens iniciais nas CMS controle de poedeiras e matrizes $\left(\mathrm{PC}=5,6 \log _{10} \mathrm{UFC} \cdot \mathrm{g}^{-1}\right.$ e $\mathrm{MC}=5,2 \log _{10}$ UFC. $^{-1}$ ) foram inferiores aos valores relatados por Kumar, Pedersen-Wismer e Caspersen (1986) $\left(7,3 \log _{10}\right.$ UFC. $\left.g^{-1}\right)$. Porém foram próximos ao valor encontrado por Maxcy, Froning e Hartung (1973), os quais detectaram uma contagem microbiológica inicial de 5,0 $\log _{10}$ UFC.g ${ }^{-1}$, bem como aos valores encontrados por Xavier e Beraquet (1994) em CMS de dorso de frango $\left(4,5 \log _{10}\right.$ UFC.g $\left.{ }^{-1}\right)$.

É possível observar que independentemente do tratamento ou do tipo de galinha utilizado, ocorreu uma diminuição na 


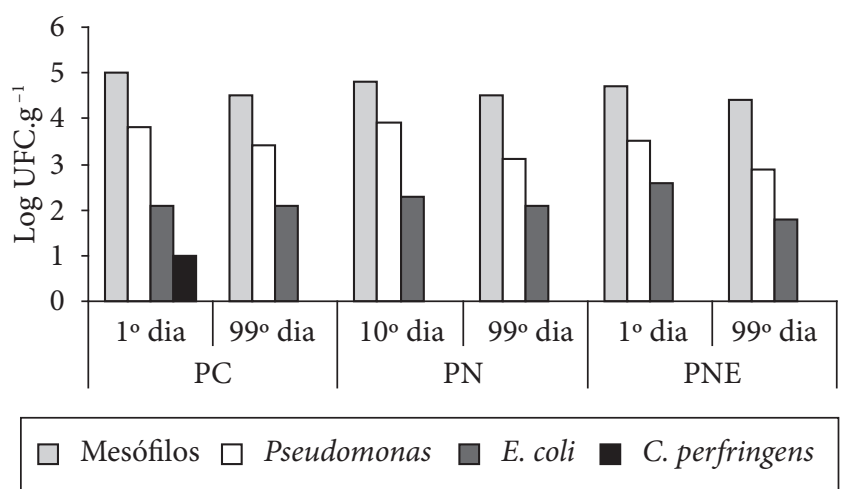

Figura 1. Variação na contagem média de mesófilos aeróbios, Pseudomonas spp., E. coli e C. perfringens durante a estocagem congelada das CMS de galinhas poedeiras controle (PC) e tratadas com nitrito $(150 \mathrm{ppm}, \mathrm{PN})$ e nitrito mais eritorbato $(150 \mathrm{ppm}+500 \mathrm{ppm}$, PNE) durante armazenamento de 99 dias a $-18^{\circ} \mathrm{C}$.

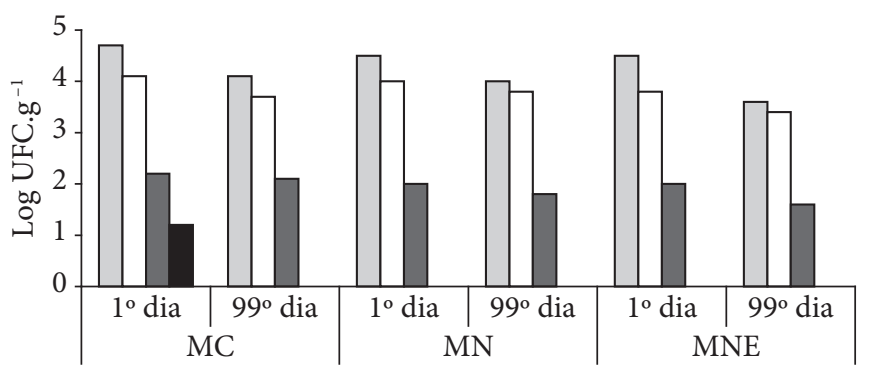

Mesófilos $\square$ Pseudomonas

E. coli

C. perfringens

Figura 2. Variação na contagem média de mesófilos aeróbios, Pseudomonas spp., E. coli e C. perfringens durante a estocagem congelada das CMS de galinhas matrizes controle (MC) e tratadas com nitrito $(150 \mathrm{ppm}, \mathrm{MN})$ e nitrito mais eritorbato $(150 \mathrm{ppm}+500 \mathrm{ppm}$, $\mathrm{MNE}$ ) durante armazenamento de 99 dias a $-18^{\circ} \mathrm{C}$.

contagem microbiológica ao longo do tempo. Esta perda da viabilidade celular ocorrida durante o período de armazenamento a $-18^{\circ} \mathrm{C}$ foi mais acentuada até o $57^{\circ} \mathrm{dia}$, permanecendo praticamente estável depois do $71^{\circ}$ dia.

Assim como para as contagens de Pseudomonas spp., E. coli, C. perfringens e mesófilos não foi verificado um efeito significativo $(p>0,05)$ do nitrito ou do nitrito mais eritorbato na estabilidade microbiológica de microrganismos psicrotróficos. A justificativa para o baixo efeito bactericida do nitrito pode ter dois principais fatores contribuintes. O primeiro é que pelo fato da CMS possuir um $\mathrm{pH}$ naturalmente mais elevado $(6,4-6,7)$ implicaria em uma não conversão do nitrito em ácido nitroso, que é a forma de maior poder bactericida (SHANK; SILLIKER; HARPER, 1962). O segundo fator seria as altas concentrações de ferro presentes na CMS. Tompkin, Christiansen e Shaparis (1979) demonstraram a relação entre o aumento do teor de ferro e a diminuição da atividade antibotulínica do nitrito. Estes pesquisadores sugeriram que o ferro reage com o óxido nítrico produzido através do nitrito e deste modo reduz a concentração de óxido nítrico, que por sua vez deveria reagir com o composto de ferro contido no interior da célula vegetativa. Segundo. Bushway, Ficker e Jen (1982), é altamente possível que

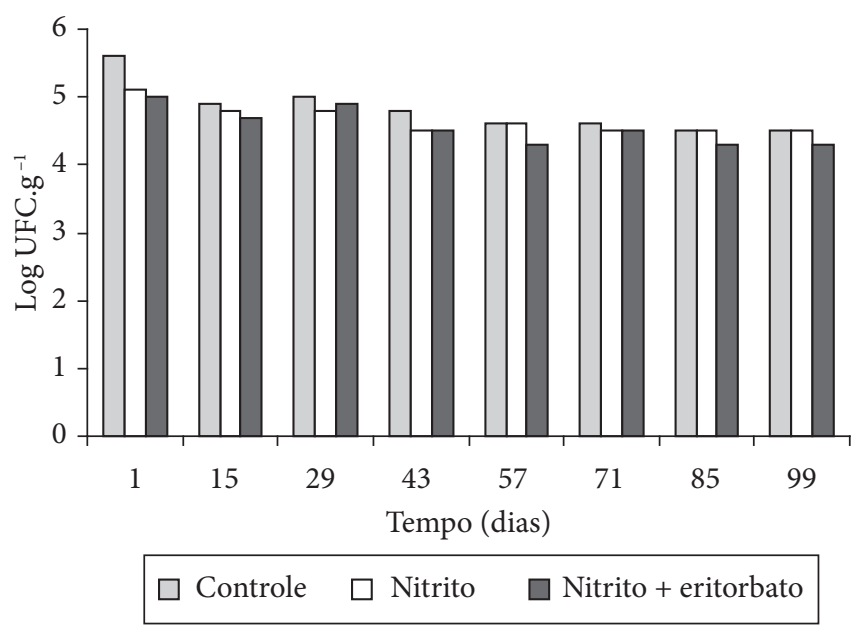

Figura 3. Contagem média dos microrganismos psicrotróficos em CMS de galinhas poedeiras controle (PC) e tratadas com nitrito $(150 \mathrm{ppm}$, $\mathrm{PN})$ e nitrito mais eritorbato $(150 \mathrm{ppm}+500 \mathrm{ppm}$, PNE) durante armazenamento de 99 dias a $-18^{\circ} \mathrm{C}$.

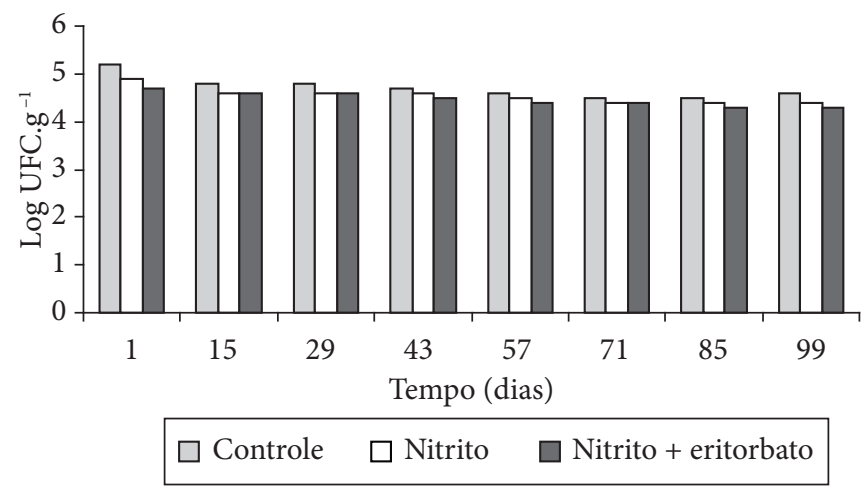

Figura 4. Contagem média dos microrganismos psicrotróficos em CMS de galinhas matrizes controle (MC) e tratadas com nitrito (150 ppm, $\mathrm{MN})$ e nitrito mais eritorbato $(150 \mathrm{ppm}+500 \mathrm{ppm}$, MNE) durante armazenamento de 99 dias a $-18^{\circ} \mathrm{C}$.

reações similares ocorram para a inibição de bactérias aeróbias através do nitrito.

A ausência do efeito do nitrito e do nitrito mais eritorbato encontrada nesse experimento está de acordo com a afirmação de Bjirker, Logtestijn e Mossel (1987), de que o ato de pré-curar as carcaças (matéria-prima para a obtenção da CMS) com nitrito em uma concentração de até $0,6 \%$ não deve ser adotado, pois se observa apenas um efeito bacteriostático superficial, sendo a deterioração de fato mascarada.

A diminuição pouco acentuada observada nas contagens dos microrganismos psicrotróficos durante a estocagem congelada pode ser justificada em função da inexistência do processo de desnaturação das proteínas celulares e subseqüente processo de floculação, que é mais intenso em temperaturas de armazenamento superiores a $-10^{\circ} \mathrm{C}$ (DELAZARI, 1980). Deste modo, a sobrevivência de microrganismos em carnes congeladas é maior em temperaturas de estocagem mais baixas, como a usada nesse experimento, que foi de $-18^{\circ} \mathrm{C}$. 
De acordo com Nurmi e Ring (1999), se o número de bactérias na superfície da carne exceder $10^{8} \mathrm{UFC}^{-1}{ }^{-1}$, a carne estará inviável para o consumo humano. Se a contagem for de $10^{7}$ UFC. $^{-1}$, a carne não terá boa qualidade, e sendo assim, esse material não poderá ser considerado matéria-prima para a obtenção de CMS. Por outro lado, é possível observar que as CMS do presente trabalho apresentaram uma contagem entre 4 a $5 \log _{10}$ UFC.g ${ }^{-1}$, após 99 dias de armazenamento a $-18{ }^{\circ} \mathrm{C}$, podendo então ser considerada adequada sua utilização em produtos cárneos.

\section{Conclusão}

Os tratamentos controle das CMS das duas linhagens de galinhas avaliadas, bem como as CMS adicionadas de nitrito e nitrito e eritorbato, apresentaram contagens de microrganismos psicrotróficos que proporcionaram estabilidade, mantendo-se adequadas para consumo durante todo o período de armazenamento. A adição de nitrito e eritorbato nas CMS também favoreceu a estabilidade dos pigmentos, permitindo melhor conservação da cor vermelha desejável ao longo do tempo. $\mathrm{O}$ tratamento com adição de nitrito e eritorbato promoveu estabilidade oxidativa na CMS de galinhas matrizes durante todo o período de armazenamento (99 dias), e por um período menor (em torno de 43 dias) na CMS de galinhas poedeiras. Assim, pode-se considerar que a mistura de nitrito e eritorbato (150 e 500 ppm, respectivamente) antes da estocagem congelada de CMS de galinhas matrizes é um tratamento efetivo para prolongar a vida útil desta matéria-prima.

\section{Agradecimentos}

À Fundação de Amparo à Pesquisa do Estado de São Paulo (FAPESP) por viabilizar a execução do Projeto "Características físico-químicas, microbiológicas, nutricionais e tecnológicas de carne mecanicamente separada de galinhas de descarte" (Processo n 99/11489-1).

\section{Referências bibliográficas}

ANVISA. Agência Nacional de Vigilância Sanitária. Resolução RDC no 12, 12 jan. 2001. Disponível em: <http://www.anvisa.gov.br/ legis/resol/12_01rdc.htm>. Acesso em: 11 jan. 2007.

AVISITE. Disponível em. <http://www.avisite.com.br/economia/ prodfran.asp >. Acesso em: 25 maio 2006.

BERAQUET, N. J. Carne mecanicamente separada de aves. In: SEMINÁRIO E CURSO TEÓRICO-PRÁTICO “AGREGANDO VALOR A CARNE DE AVES”. Campinas: CTC/ITAL, 2000.

BRASIL. Ministério da Agricultura e Abastecimento - Secretaria de Defesa Agropecuária. Métodos Analíticos para Controle de Produtos Cárneos e seus Ingredientes - Métodos Físicos químicos. Portaria no 001/81, 07 out. 1981. p. I-3.

BiJKer, P. G. H.; LOGTestijN, J. G. van; MOssel, D. A. A. Bacteriological quality assurance (BQA) of Mechanically Deboned Meat (MDM). Meat Science, Oxford, v. 20, n. 4, p. 237-252, 1987.

BUSHWAY, A. A.; FICKER, N.; JEN, C.W. Effect of nitrite and sorbate on total number of aerobic microorganisms in chicken white and dark meat patties. Journal of Food Science, Chicago, v. 47, n. 3, p. 858-860, 863, 1982.
CARPENTER, C. E.; REDDY, D. S. A.; CORNFORTH, D. P. Inactivation of clostridial ferredoxin and pyruvate-ferredoxin oxidoreductase by sodium nitrite. Applied Environmental Microbiology, Washington, v. 53, n. 3, p. 549-552, 1987.

COUNSELL, J. N.; HORNIG, D. H. Vitamin C (ascorbic acid). England: Applied Science, 1981. Cap. 7.

DELAZARI, I. Microbiologia de alimentos congelados. I. Efeito do congelamento sobre os microrganismos. Boletim do ITAL, Campinas, v. 17, n. 1, p. 15-30, 1980.

DENG, J. C. et al. Ascorbic acid as antioxidant in fish flesh and its degradations. Journal of Food Science, Chicago, v. 43, n. 3, p. 457-460, 1978.

FIELD, R. A. Mechanically separated meat, poultry and fish. In: PEARSON, A. M.; DUTSON, T. R. (Eds). Edible Meat By-Products, p. $83-128,1988$.

GRAY, J. I; GOMAA, E. A.; BUCLKEY, D. J. Oxidative quality and shelf life of meats. Meat Science, Oxford, v. 43, n. S, p. S111-S123, 1996.

GRAY, J. I.; PEARSON, A. M. Rancidity and warmed over flavor in Advances in Meat Reseach, v. 3, AVI Book, New York, 1987.

HASIAK, R. J. et al. Effect of sodium nitrite and sodium eritorbate on the chemical, sensory and microbiological properties of water-adde turkey ham. Poultry Science, (Savoy), v. 63, n. 7, p. 1364-1371, 1984.

JANTAWAT, P.; DAWSON, L. E. Composition of lipids from mechanically deboned poultry meats and their composite tissues. Poultry Science, Savoy, v. 59, n. 5, p. 1043-1052, 1980.

KOLODZIEJSKA, I; SKONIECSNY, S.; RUBIN, L. J. Malondialdehydenitrite interactions in meat and model systems. Journal of Food Science, Chicago, v. 55, n. 4, p. 925-928, 946, 1990.

KUMAR, S.; PEDERSEN-WISMER, J.; CASPERSEN, C. Effect of raw materials, deboning methods and chemical additives on microbial quality of mechanically deboned poultry meat during frozen storage. Journal of Food Science and Technology, New Jersey, v. 23, n. 4, p. 217-220, 1986.

LEE, Y. B. et al. Mechanism of lipid oxidation in mechanically deboned chicken meat. Journal of Food Science, Chicago, v. 40, n. 5, p. 964-967, 1975.

MAC DONALD, B; GRAY, J. I.; GIBBINS, L. N. Role of nitrite in cured meat flavor: antioxidant role of nitrite. Journal of Food Science, Chicago, v. 45, n. 4, p. 893-897, 1980.

MAXCY, R. B.; FRONING, G. W.; HARTUNG, T. E. Microbial quality of ground poultry meat. Poultry Science, Savoy, v. 52, n. 2, p. $486-489,1973$.

McNEILL, J.; KAKUDA, Y. Influence of carcass parts and food additives on the oxidative stability of frozen mechanically separated and hand-deboned chicken meat. Poultry Science, Savoy, v. 67, n. 2, p. 270-274, 1988.

McMINDES, M. K.; SIEDLER, A. J. Nitrite mode of action: inhibition of yeast pyruvate decarboxylase (E.C. 4.1.1.1) and clostridial pyruvate:ferredoxin oxidoreductase (E.C. 1.2.7.1) by nitric oxide. Journal of Food Science, Chicago, v. 53, n. 3, p. 917-919-931, 1988.

MEAD, G. C.; ADAMS, B. W. A selective medium for the rapid isolation of Pseudomonads associated with poultry meat spoilage. British Poultry Science, London, v. 18, n. 6, p. 661-667, 1977.

MOERCK, K. E.; BALL JR., H. R. Lipid autoxidation in mechanically deboned chicken meat. Journal of Food Science, Chicago, v. 39, n. 5, p. 876-879, 1974. 
MORRISEY, P. A. et al. Lipid stability in meat and meat products. Meat Science, Oxford, v. 49, n. Suppl. L, p. S73-S86, 1998.

NURMI, E.; RING, C. Production of hygienically justifiable mechanically recovered meat. Fleischwirtscaft International, Frankfurt, v. 2, n. 1, p. 21-22, 1999.

POLLONIO, M. A. R. Estudo das propriedades funcionais das proteínas miofibrilares e oxidação lipídica de carne de frango mecanicamente desossada, 1994. 141 p. Tese (Doutorado) - FEA/ UNICAMP, Campinas, 1994.

PRICE, J. F.; SCHWEIGERT, B. S. The Science of Meat and Meat Products. 2. ed. San Francisco: W. H. Freeman and Company, 1971.

SHANK, J. L.; SILLIKER, J. H.; HARPER, R. H. The effect of nitric oxide on bacteria. Journal of Applied Microbiology, Oxford, v. 10, n. 3, p. 185-189, 1962.

SILVA, R. Z. M. Technologie und mikrobiologie voraussetzung zur herstellung sicherer und stabiler rohpökelwaren aus geflügelfleish, 1994. 113p. Tese (Doutorado) - Technische Universität Berlin, Berlin, 1994.

TERRA, N. N. Apontamentos de Tecnologia de Carnes. São Leopoldo: Ed. Unisinos, 1998. 216p.

TOMPKIN, R. B. Microbiology of ready-to-eat meat and poultry products. In: PEARSON, A. M.; DUTSON, T. R. Advances in Meat Reseach, v. 2, Westport, AVI Publishing Co. 1986, p. 89-118.
TOMPKIN, R. B.; CHRISTIANSEN, L. N.; SHAPARIS, A. B. Iron and antibotulinum efficacy of nitrite. Applied Environmental Microbiology, Washington, v. 37, n. 2, p. 351-353, 1979.

VANDERZANT, C.; SPLITTSTOESSER, D. F. Compendium of methods for the microbiological examination of foods. 3. ed. Washington: American Public Health Association-APHA, 1992. 1919p.

VINCKE, W. Evaluation of the direct thiobarbituric acid extration method for determining oxidative rancidity in mackerel (Scomber scombrus L.). Fette-Seifen Anstrichmittel, Hamburg, v. 77, n. 6, p. 239-240, 1975.

XAVIER, C. V. A.; BERAQUET, N. J. Vida-de-prateleira de carne mecanicamente separada de frango estocada sob refrigeração. Coletânea do Instituto de Tecnologia de Alimentos, Campinas, v. 1, n. 24, p. 91-104, 1994.

WESLEY, R. L.; MARION, W. W.; SEBRANEK, J. G. Effect of sodium nitrite concentration, sodium erythorbate and storage time on the quality of franks manufactured from mechanically deboned turkey. Journal of Food Science, Chicago, v. 47, n. 5, p. 1626-1630, 1982.

WHITE, C. A.; HALL, L. P. The effect of temperature abuse on Clostridium perfringens and Bacillus cereus in raw beef and chicken substrates during frozen storage. Food Microbiology, Amsterdam, v. 1, n. 2, p. 97-104, 1984. 